Research Article

\title{
Evaluation of Heavy Metal and Microbial Contamination in Green Tea and Herbal Tea Used for Weight Loss in the Palestinian Market
}

\author{
Murad N. Abualhasan (D, ${ }^{1}$ Nidal jaradat $\left(\mathbb{D},{ }^{1}\right.$ Mohammed Hawash, ${ }^{1}$ Rama Khayat, ${ }^{1}$ \\ Eman Khatatbeh, ${ }^{1}$ Malak Ehmidan, ${ }^{1}$ and Munir Al-Atrash ${ }^{2}$ \\ ${ }^{1}$ Faculty of Medicine and Health Sciences, Department of Pharmacy, An-Najah National University, Nablus, State of Palestine \\ ${ }^{2}$ Jerusalem Pharmaceutical Company, Quality Control Department, Ramallah, State of Palestine \\ Correspondence should be addressed to Murad N. Abualhasan; m_abualhasan@najah.edu
}

Received 21 June 2020; Revised 25 October 2020; Accepted 31 October 2020; Published 10 November 2020

Academic Editor: Christopher Worsnop

Copyright (C) 2020 Murad N. Abualhasan et al. This is an open access article distributed under the Creative Commons Attribution License, which permits unrestricted use, distribution, and reproduction in any medium, provided the original work is properly cited.

\begin{abstract}
The use of green tea and herbal tea for weight loss is increasing worldwide owing to the rising rates of obesity. There are concerns about the safety and quality of these herbal products owing to their increased consumption worldwide. In this study, we evaluated randomly collected samples of green tea and herbal tea and tested them for heavy metal and microbial contamination. Eighteen samples of green tea or herbal tea of widely used brands in Palestine were tested for heavy metal and microbial contamination. The results showed that 7 of the samples had toxic heavy metals such as chromium $(\mathrm{Cr})$ and lead $(\mathrm{Pb})$, and their concentrations were above the allowable limits set by the World Health Organization (WHO). Moreover, 6 of the samples that were tested had microbial contamination with high total aerobic microbial count (TAMC) and total yeast and mold count (TYMC). This could be due to improper handling and storage conditions of these herbal products. This study is the first of its kind in Palestine, and its results are forewarning to all the responsible authorities, including the Ministry of Health $(\mathrm{MoH})$, to take immediate corrective actions such as quality control testing, auditing, and registration of marketed tea products.
\end{abstract}

\section{Introduction}

The use of green tea and herbal tea for weight loss has been increasing worldwide, concomitantly with the rates of obesity $[1,2]$. These products are easily accessible, trusted, easy to use, inexpensive, and thought to be safer compared to conventional medications. These factors led to an increased use of these types of teas $[3,4]$. Globally, tea is the second most consumed drink after water [5]. Three billion kilograms of tea are produced each year worldwide [6]. Nearly $20 \%-22 \%$ of the total tea consumption is of green tea, primarily in China, Japan, Korea, Morocco, and few other countries in North Africa and the Middle East $[5,7,8]$.

Green tea is "nonfermented" and obtained from $\mathrm{Ca}$ mellia sinensis, whereas other herbal teas used for weight loss are from several other tea plants, which are sometimes used in combination with green tea. These include Pimpinella anisum, Mangifera indica, Garcinia gummi-gutta, Terminalia bellirica, Aloysia citrodora, Matricaria chamomilla, Centaurea cyanus, Urtica, Eucalyptus globulus, Plantago ovata, Laurus nobilis, Tilia europaea, Cymbopogon citratus, Mentha spicata, Rosa canina, Echinacea angustifolia, Terminalia chebula, Vaccinium oxycoccos, Cuminum cyminum, Zingiber officinale, Salvia officinalis, Cinnamomum verum, Foeniculum vulgare, Portulaca oleracea, and Senna italica $[5,9]$.

Huge concerns about the safety and quality of herbal products have been rising. This is due to the rapid and widespread increase in the consumption of herbal products over the last few years [10]. The level of heavy metal contamination in herbal products is recommended to be minimal because these consequently add to the level that has 
already been consumed through daily diet [10]. The allowable limits of heavy metals depend on the nature adjusted according to regional or national variations [10]. The allowable limits of selected heavy metals in edible medicinal plants, according to international guidelines, are provided in Table 1.

Microbial contamination in herbal products may occur at any stage of product preparation, from planting and harvesting to packaging, distribution, and storage. The presence of microorganisms at certain levels may indicate poor quality of such products [11]. The allowable limits of microbial contamination vary according to the type of herb and its intended use [10]. The allowable limits of microbial contamination in herbal products recommended by the WHO are the total aerobic microbial count (TAMC) must not exceed $10^{7} \mathrm{CFU} / \mathrm{g}$; the total yeast and mold count (TYMC) must not exceed $10^{5} \mathrm{CFU} / \mathrm{g}$; and these products must be free from Clostridium difficile, Salmonella, and Shigella.

Currently, there is an inclination towards widely using different types of herbal products as complementary and alternative medicine in Palestine, owing to the biodiversity in this area [12]. Herbal products in the Palestinian market are regulated and controlled by the Ministry of Health $(\mathrm{MoH})$ through the General Administration of Pharmacy by the Drug Registration Department. This department is responsible for the registration of imported herbal products and food supplements. The affiliated quality control department is responsible for quality testing and implementing the rules of Good Manufacturing Procedure (GMP) for medicinal herbs packed in Palestinian establishments. The laws and regulations regarding herbal products have been recently established and updated. The $\mathrm{MoH}$ has the right to withdraw any herbal products that prove to have a dangerous side effect. The recommendations of the $\mathrm{MoH}$ on the allowable limits of heavy metals in herbal medicine are based on the recommendations of the WHO and Food and Agriculture Organization (FAO) [13-15]. However, there is still a gap in implementing these rules and regulations with regular quality testing for microbial and heavy metal contamination in green tea and herbal tea that are sold in the Palestinian market [16].

Several studies were carried out globally to evaluate the contamination in herbal products. These were conducted in countries, such as Pakistan, Tanzania [17-20], Italy [21], Ghana [22], Nigeria [23], Brazil [24], South Africa [25] and some Arab countries, such as Palestine, Saudi Arabia, the United Arab Emirates, and Egypt [26-30]. The main objective of these studies was to detect the presence of microbial and/or heavy metal contamination, such as lead $(\mathrm{Pb})$, cadmium (Cd), manganese (Mn), iron (Fe), chromium (Cr), zinc $(\mathrm{Zn})$, mercury $(\mathrm{Hg})$, nickel $(\mathrm{Ni})$, and arsenic (As) in some common medicinal plants and types of teas and to assess their safety according to international limits.

The results of these studies showed that manganese and cobalt exceeded the allowable limits [31]. Another study in Tanzania showed that the concentrations of $\mathrm{Mg}, \mathrm{Mn}, \mathrm{Fe}$, and $\mathrm{Ni}$ in medicinal plants were higher than the allowed limits [32]. It is important to emphasize that even if the heavy metal contamination is within the internationally accepted limits, there is still a high chance of accumulation of these elements in the body that reach toxic levels [33]. In the Middle East, the results of several studies showed that the heavy metals, such as $\mathrm{Pb}, \mathrm{Cd}, \mathrm{Cu}$, and $\mathrm{Zn}$ in the herbal samples that were tested, were above the allowable limits. These results indicate that long-term use of contaminated herbal products may pose a potential health risk to consumers $[23,34,35]$. A comparative assessment of the quality of commercial black and green tea was conducted in Italy to check microbial and fungal contamination (total bacterial count, fungi, Escherichia coli, Pseudomonas spp., and Clostridium perfringens). The study showed that there was no microbial contamination that could be harmful to consumers, except for the contamination by mycotoxins such as ochratoxin A, which was above the allowable limits in food products in 50\% of analyzed samples [36].

The objective of our study was to perform a quality check for the microbial and heavy metal contamination in green tea and herbal tea that claims to aid weight loss and is widely used among the Palestinian population. The results of the study reflected the actual situation of this problem in Palestine and will help raise the issue of contamination in herbal products to the concerned authorities.

\section{Materials and Methods}

2.1. Chemicals and Reagents. The following reagents were used throughout this study: tryptic soy agar (Difco Laboratories, Detroit, USA), Sabouraud dextrose agar (Difco ${ }^{\mathrm{TM}}$; France) (for preparing the medium), tryptic soy broth (Difco $^{\mathrm{TM}}$; France), and Tween 80 (Difco $^{\mathrm{TM}}$; France), which was used to prepare Fluid 3 for microbiological testing. Nitric acid (70\%) (Riedel-de Haen, Seelze, Germany) and perchloric acid (70\%-72\%) (Riedel-de Haen, Seelze, Germany) were used for acid digestion of the herbal samples.

2.2. Instrumentation. An atomic absorption spectrometer (model: iCE 3000; Thermo Fisher Scientific) was used for the quantitative analysis of heavy metals. An autoclave (model: DLOV 3764; De Lama) was used for the sterilization of Fluid 3 (F3) and the agar mediums. A laminar air flow chamber (BBS-V1300; Biobase) and incubators (BC3100-R1; Biorold) were used for microbiological testing of the herbal samples, and Vortex Genie 2 was used for sample mixing.

2.3. Collection of Tea Samples. Eighteen samples were collected from either herbal medicine shops or community pharmacies. The samples were either green tea or herbal tea used for weight loss belonging to widely used brands in Palestine. Each tea sample was from a different brand, and the samples were either packed locally in Palestine or imported. The collected tea samples were primarily and widely used for weight loss.

All the samples that were collected were fine particles; thus, the samples did not require any further processing before experimentation. 
TABLE 1: Examples of allowable limits of toxic heavy metals according to the World Health Organization (WHO).

\begin{tabular}{lcc}
\hline Element & For edible plants $(\mathrm{mg} / \mathrm{kg})$ & For medicinal plants $(\mathrm{mg} / \mathrm{kg})$ \\
\hline Nickel $(\mathrm{Ni})$ & 1.63 & 1.5 \\
Copper $(\mathrm{Cu})$ & 3 & 10 \\
Zinc $(\mathrm{Zn})$ & 27.4 & 50 \\
Cadmium $(\mathrm{Cd})$ & 0.2 & 0.3 \\
Lead $(\mathrm{Pb})$ & 0.43 & 10 \\
Chromium $(\mathrm{Cr})$ & 0.02 & 1.3 \\
\hline
\end{tabular}

They were stored in airtight glass containers in a dark, dry, and cool place during the period of the study.

\subsection{Elemental Analysis}

2.4.1. Acid Digestion of the Herbal Sample. The acid digest was prepared by oxidizing $0.2 \mathrm{~g}$ of the dry powder from tea bags, with $10 \mathrm{~mL}$ of an acid mixture of $2: 1$ ratio (nitric acid: perchloric acid), which was then stirred and kept overnight at room temperature. The mixture was then filtered, and $1 \mathrm{~mL}$ of the filtrate was diluted to $25 \mathrm{~mL}$ with distilled water. The diluted samples were used in the quantitative measurement of $\mathrm{Pb}, \mathrm{Cd}, \mathrm{Cu}, \mathrm{Ni}, \mathrm{Cr}$, and $\mathrm{Zn}$, using an atomic absorption spectrophotometer. These samples were prepared in triplicate for each tea brand, and each of those were tested three times; the average values and standard deviations were recorded.

2.4.2. Quantitative Elemental Analysis. For analysis, four standard concentrations of each heavy metal were prepared. The digested samples were diluted with water to be within the range of the calibration curve. The concentrations of the heavy metals in the samples were determined using the calibration curve and regression equation [37]. The fourpoint calibration of the concentration for each heavy metal that was studied is provided in Table 2.

2.5. Microbiological Testing. The tests for bacterial and fungal contamination were conducted according to the United States Pharmacopoeia (USP) [38]. Fluid 3 "F3," a medium which was prepared by adding $15 \mathrm{~g}$ tryptic soy broth to $500 \mathrm{~mL}$ distilled water and $1 \mathrm{~mL}$ of Tween 80 , was used to test for bacterial growth. Another medium was prepared by suspending $40 \mathrm{~g}$ of the powder of tryptic soy agar in $1 \mathrm{~L}$ of purified water. The mixture was thoroughly stirred with heat and boiled for $1 \mathrm{~min}$ to dissolve the powder completely.

Sabouraud dextrose agar was used to test for yeast and fungal growth. It was prepared by dissolving $65 \mathrm{~g}$ of the powder in $1 \mathrm{~L}$ of purified water, mixed thoroughly with heat, and frequently agitating to dissolve the powder completely. The agar medium was autoclaved at $121^{\circ} \mathrm{C}$ for $15 \mathrm{~min}$. This medium was then used for the inoculation of fungi. The medium was placed in an oven at $50^{\circ} \mathrm{C}$ to maintain the liquid phase and was used whenever required.

Consequently, dry tea samples $(3 \mathrm{~g})$ were added to the corresponding preparations of Fluid $3(30 \mathrm{~g})$. The samples were diluted to prepare the following concentrations: $10,10^{2}$,
$10^{3}$, and $10^{4}$. Each dilution was inoculated on plates of tryptic soy agar and were incubated at $30-35^{\circ} \mathrm{C}$ for $48 \mathrm{~h}$ for bacterial identification. Fungal testing was performed by inoculating the prepared dilutions on plates of Sabouraud dextrose agar and incubating the plates at $20-25^{\circ} \mathrm{C}$ for 5 days. The results were reported as colony-forming units (CFU) per gram or $\mathrm{mL}$.

2.6. Statistical Analysis. The Statistical Package for the Social Sciences software (SPSS) was used to perform descriptive statistical analysis. Analysis of variance (ANOVA) was used to test if there was a statistically significant difference between the average values. Pearson's chi-squared test was used to determine whether there was a significant difference between the expected and observed frequencies of more than one category. In all the statistical tests, if the $p$ value was less than 0.05 , the null hypothesis was rejected, and it was concluded that a significant difference exists.

\section{Results and Discussion}

Products for weight loss that are made from natural sources are widely used by consumers because of their belief in its safety. Green tea is one of the most common natural ingredients in over-the-counter products for weight loss, which are available worldwide. A total of 18 samples of different brands of tea were analyzed for heavy metal and microbial contamination. The samples were either of green tea or herbal tea, which is frequently used by people who follow weight loss regimens. The majority of the tested samples were of green tea $(60 \%)$, while other herbal teas constituted $39 \%$ of the tested samples. These percentages reflect the consumption by the public because a majority of the people think that green tea is safer as well as cheaper than other herbal teas for weight loss (Figure 1).

The tea samples were either locally packed or imported from other countries. Majority of the samples were imported from other countries ( $89 \%)$, while the rest $(11 \%)$ were from local sources (Figure 1). The source of tea sample reflects the trends in selling herbal products in the local Palestinian market. The majority of herbal products, which are sold as weight loss products, are imported. There are only few local manufacturers of herbal medicine in Palestine; thus, their share in the local market is low compared to the imported products [39].

The results of the test for heavy metal contamination in the samples showed that all the samples had passed the test for $\mathrm{Cu}, \mathrm{Ni}$, and $\mathrm{Cd}$ and failed the test for Cr. Additionally, 3 of the samples had failed the test for $\mathrm{Pb}$. The concentration of 
TABLE 2: Calibration of concentration for each heavy metal.

\begin{tabular}{lcccccc}
\hline Metals & $\mathrm{Ni}(\mathrm{ppm})$ & $\mathrm{Cu}(\mathrm{ppm})$ & $\mathrm{Zn}(\mathrm{ppm})$ & $\mathrm{Cd}(\mathrm{ppm})$ & $\mathrm{Pb}(\mathrm{ppm})$ & $\mathrm{Cr}(\mathrm{ppm})$ \\
\hline Standard \#1 & 0.05 & 0.5 & 0.5 & 0.5 & 1 & 0.5 \\
Standard \#2 & 0.1 & 1 & 1 & 2 & 2.5 & 1 \\
Standard \#3 & 0.5 & 2 & 2 & 3 & 2 \\
Standard \#4 & 1 & 3 & 3 & & 10 & 3 \\
\hline
\end{tabular}

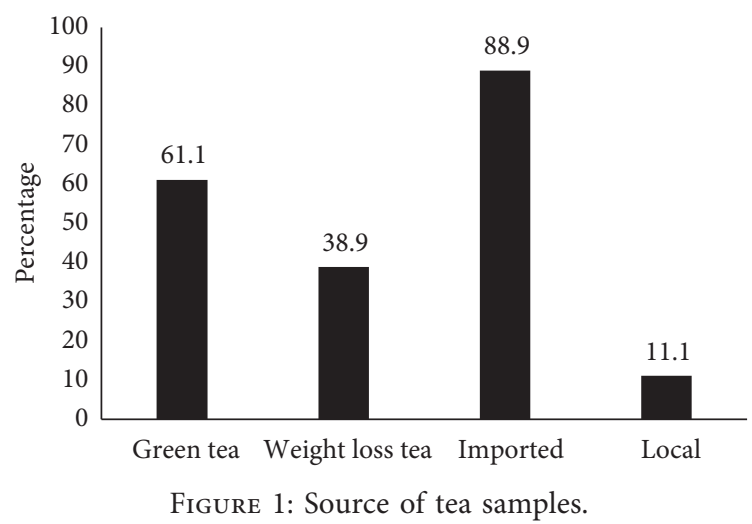

TABle 3: Concentration (ppm) of each heavy metal that was identified.

\begin{tabular}{|c|c|c|c|c|c|c|c|c|c|c|c|c|}
\hline No. & Lead $(\mathrm{Pb})$ & & Nickel (Ni & & Chrome $(\mathrm{C}$ & & Zinc $(\mathrm{Zn})$ & & Copper $(\mathrm{C}$ & & Cadmium (C & \\
\hline 1 & $0.101 \pm 0.0103$ & Pass & $0.248 \pm 0.0270$ & Pass & $0.234 \pm 0.0340$ & Fail & $0.063 \pm 0.0088$ & Pass & $0.029 \pm 0.0210$ & Pass & $0.011 \pm 0.0109$ & Pass \\
\hline 2 & $0.110 \pm 0.0303$ & Pass & $0.355 \pm 0.0151$ & Pass & $0.251 \pm 0.0460$ & & $0.074 \pm 0.002$ & Pass & $0.042 \pm 0.0359$ & Pass & $0.012 \pm 0.0015$ & Pass \\
\hline 3 & $0.111 \pm 0.0101$ & Pass & $0.363 \pm 0.0010$ & Pass & $0.295 \pm 0.0247$ & $\mathrm{~F}$ & $0.118 \pm 0.010$ & & $0.534 \pm 0.8439$ & Pass & $0.012 \pm$ & \\
\hline & $0.122 \pm 0.0303$ & Pass & $0.421 \pm 0.0242$ & Pass & $0.345 \pm 0.0223$ & Fail & $0.121 \pm 0.0087$ & Pass & $.019 \pm$ & Pass & 0.014 & \\
\hline 5 & $0.123 \pm 0.0030$ & Pass & $0.449 \pm 0$ & Pass & $0.386 \pm 0$ & & $0.124 \pm 0$ & Pass & $0.014 \pm$ & Pass & 0.011 & \\
\hline 6 & $0.112 \pm 0.0122$ & Pass & $0.455 \pm 0.0480$ & Pass & $0.424 \pm 0.0170$ & Fail & $0.156 \pm 0.0482$ & Pass & $0.018 \pm 0.0171$ & Pass & & \\
\hline 7 & $0.110 \pm 0.0123$ & Pass & $0.514 \pm 0.0359$ & Pass & $0.462 \pm 0.003$ & Fail & $0.111 \pm 0.0011$ & Pass & $0.033 \pm 0.0241$ & Pass & 0.019 & Pass \\
\hline 8 & $0.134 \pm 0.0332$ & Pass & $0.487 \pm 0.0$ & Pass & $0.473 \pm$ & & $0.117 \pm$ & $\mathrm{Pa}$ & 0.033 & Pass & 0.0 & \\
\hline 9 & $0.123 \pm 0.0$ & Pass & $0.539 \pm 0$ & Pass & $0.495=$ & & $0.159 \pm$ & Iss & 0.027 & Pass & & ass \\
\hline 10 & $0.110 \pm 0.0101$ & Pass & $0.564 \pm 0.0270$ & Pass & $0.522=$ & Fail & $0.137 \pm$ & Pass & $0.039=$ & Pass & 0.01 & Pass \\
\hline 11 & $0.385 \pm 0.1104$ & Pass & $0.555 \pm 0.0409$ & Pass & 0.505 & Fail & $0.134 \pm$ & Pass & 0.034 & Pass & 0.031 & Pass \\
\hline 12 & $0.449 \pm 0.0397$ & Fail & $0.586 \pm$ & Pass & 0.564 & & $0.125 \pm$ & Pass & 0.021 & Pass & 0.03 & \\
\hline 13 & $0.381 \pm 0.0460$ & Pass & $0.571 \pm 0.0315$ & Pass & $0.539 \pm 0.0092$ & Fail & $0.128 \pm 0.0039$ & Pass & $0.051 \pm$ & Pass & 0.03 & Pass \\
\hline 14 & $0.374 \pm 0.0377$ & Pass & $0.579 \pm 0.0123$ & Pass & $0.640 \pm 0.0022$ & Fail & $0.171 \pm 0.0152$ & Pass & $0.121 \pm 0.0252$ & Pass & $0.041 \pm 0.0027$ & Pass \\
\hline 15 & $0.369 \pm 0.0234$ & Pass & $0.562 \pm 0.032$ & Pass & $0.560 \pm 0.0188$ & Fail & $0.132 \pm 0.0072$ & Pass & $0.037 \pm 0.0370$ & Pass & $0.045 \pm 0.0059$ & Pass \\
\hline 16 & $0.476 \pm 0.0403$ & Fail & $0.623 \pm 0.0107$ & Pass & $0.614 \pm 0.049$ & Fail & $0.139 \pm 0.0113$ & Pass & $0.013 \pm 0.0140$ & Pass & $0.050 \pm 0.0031$ & Pass \\
\hline 17 & $0.484 \pm 0.0911$ & Fail & $0.595 \pm 0.0078$ & Pass & $0.646 \pm 0.0260$ & Fail & $0.126 \pm 0.0034$ & Pass & $0.020 \pm 0.0285$ & Pass & $0.050 \pm 0.0012$ & Pass \\
\hline 18 & $0.340 \pm 0.0303$ & Pass & $0.614 \pm 0.0232$ & Pass & $0.640 \pm 0.0113$ & Fail & $0.132 \pm 0.0016$ & Pass & $0.034 \pm 0.0286$ & Pass & $0.0473 \pm 0.0044$ & Pass \\
\hline
\end{tabular}

each heavy metal that was identified in each sample are provided in Table 3.

The resulting concentration of $\mathrm{Pb}$ varied depending on the type of tea sample. Notably, all green tea samples had passed the test for $\mathrm{Pb}$, while only 4 out of 7 samples of herbal tea had passed this test (Figure 2). Therefore, we performed a chi-squared test to determine the statistical difference, and the result showed significant difference $(p=0.043)$ between green tea and herbal tea. These results show that the lead contamination is less in green tea compared to herbal tea. Herbal products for weight loss consist of a mixture of many herbs that are cultivated from many sources; therefore, some of the content may contribute to high lead levels [40]. Moreover, most of the herbal products for weight loss that are present in the Palestinian local market are not registered; thus, these items are not continuously monitored, and many of them could be adulterated and counterfeit brands [41].

Further statistical analysis was performed to determine whether the different source of the tea samples attributed to the lead contamination (Figure 3). A chi-squared test was performed to determine if the difference was statistically significant. The results clearly showed that there was no significance $(p=0.66)$. This indicates the quality of both types of teas, regardless of the source. As mentioned earlier, imported herbal products are not registered under the $\mathrm{MoH}$, and many of them are contaminated due to improper handling, storage, and packing in local Palestinian establishments [42]. 


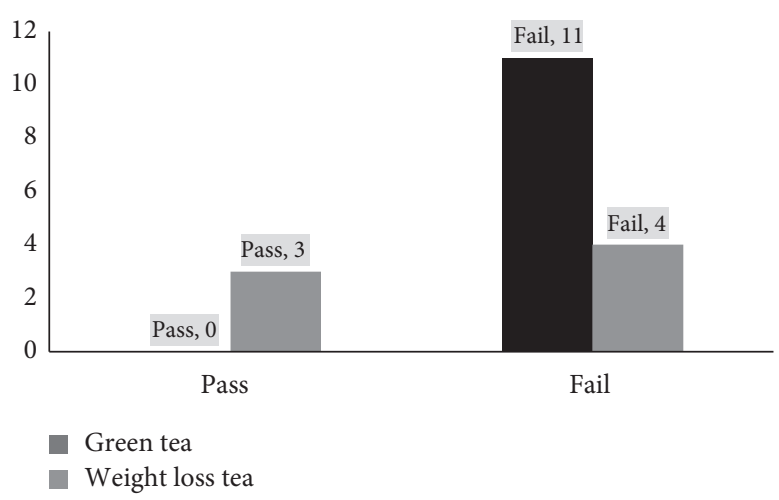

Figure 2: Concentration of lead in both types of tea samples.

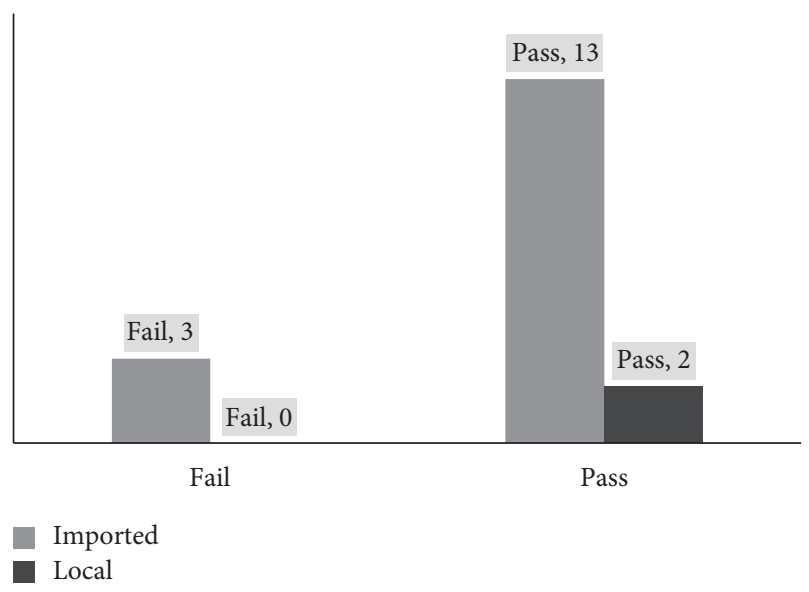

FIgure 3: Concentrations of lead in the samples based on the source.

The results of the microbial tests showed that $33 \%$ of the samples had microbial contamination.

The results of microbial tests from both sources of tea samples are shown in Figure 4 . Six out of 18 samples had failed the test; 4 of the samples had a TYMC above the allowable limit $(100 \mathrm{CFU} / \mathrm{mL})$, and 1 sample had a TAMC above the allowable limit $(1000 \mathrm{CFU} / \mathrm{mL})[43,44]$. Moreover, 1 of the sample was contaminated with E. coli. The chi-squared test showed no significant difference in contamination between the imported and the local sources of tea samples $(p=0.59)$.

The results of the microbial tests of both types of teas are shown in Figure 5. The results showed that 2 out of the 11 green tea samples had failed the microbial test, and 4 out of the 7 samples were found to have microbial contamination. The results clearly show that the herbal tea was more contaminated than green tea. This could be because most of the brands of herbal tea for weight loss were not registered under the $\mathrm{MoH}$; thus, they were not tested and did not undergo auditing. However, the chi-squared test showed no statistical significance $(p=0.12)$. Microbial contamination

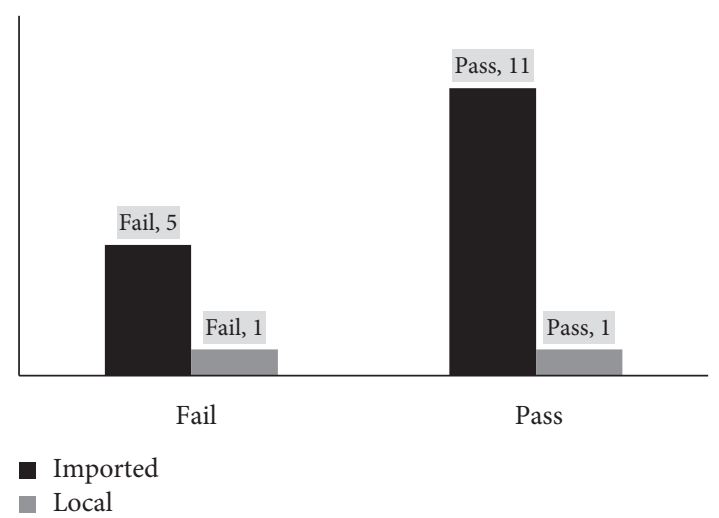

FIGURE 4: Results of microbial tests of the samples based on the source.

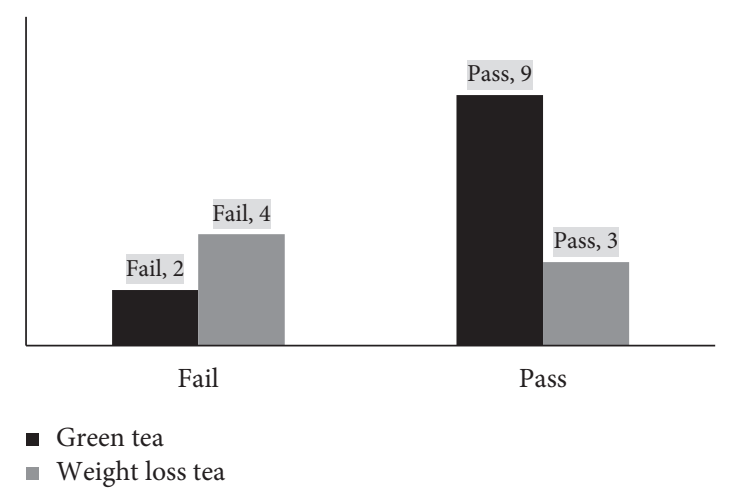

FIgURE 5: Results of microbial tests of both types of teas.

in herbal products could be attributed to improper handling during dispensing, packaging, and/or nonadherence to good manufacturing practices $[45,46]$.

\section{Conclusion}

Green tea and weight loss herbal tea are widely used in the local and international market. Contaminated herbal tea proved to have detrimental and health hazards to its users specially when taken in large amount such as this types of widely used tea. This is the first study that evaluated the heavy metal and microbial contamination in green tea and herbal tea that are widely used for weight loss in Palestine. The results showed that many of the tested samples contain toxic heavy metals such as $\mathrm{Cr}$ and $\mathrm{Pb}$, which were above the allowable limits. Moreover, majority of the tested samples had microbial contamination with E. coli, and some of the samples had TAMC and TYMC that were above the allowable limits. This study is a forewarning to all the responsible authorities, including the $\mathrm{MoH}$, to take immediate corrective actions, such as quality control testing, auditing for proper storage conditions, and registration of marketed tea products. 


\section{Data Availability}

No data were used to support this study

\section{Conflicts of Interest}

The authors declare that they have no conflicts of interest.

\section{References}

[1] C. S. Yang, J. Zhang, L. Zhang, J. Huang, and Y. Wang, "Mechanisms of body weight reduction and metabolic syndrome alleviation by tea," Molecular Nutrition \& Food Research, vol. 60, pp. 160-174, 2016.

[2] S. M. Henning, J. Yang, M. Hsu et al., "Decaffeinated green and black tea polyphenols decrease weight gain and alter microbiome populations and function in diet-induced obese mice," European Journal of Nutrition, vol. 57, pp. 2759-2769, 2018.

[3] R. Farrington, I. F. Musgrave, and R. W. Byard, "Evidence for the efficacy and safety of herbal weight loss preparations," Journal of Integrative Medicine, vol. 17, pp. 87-92, 2019.

[4] M. Kazemipoor, C. W. J. W. M. Radzi, G. A. Cordell, and I. Yaze, "Potential of traditional medicinal plants for treating obesity: a review," http://arxiv.org/abs/1208.923.

[5] C. Cabrera, R. Artacho, and R. Giménez, "Beneficial effects of green tea-a review," Journal of the American College of Nutrition, vol. 25, pp. 79-99, 2006.

[6] S. Kuriyama, T. Shimazu, K. Ohmori et al., "Green tea consumption and mortality due to cardiovascular disease, cancer, and all causes in JapanThe ohsaki study," JAMA, vol. 296, pp. 1255-1265, 2006.

[7] H. N. Graham, "Green tea composition, consumption, and polyphenol chemistry," Preventive Medicine, vol. 21, pp. 334-350, 1992.

[8] D. L. McKay and J. B. Blumberg, "The role of tea in human health: an update," Journal of the American College of $\mathrm{Nu}$ trition, vol. 21, pp. 1-13, 2002.

[9] D. O. N. Rothenberg, C. Zhou, and L. Zhang, "A review on the weight-loss effects of oxidized tea polyphenols," Molecules, vol. 23, p. 1176, 2018.

[10] World Health Organization, WHO Guidelines for Assessing Quality of Herbal Medicines with Reference to Contaminants and Residues, World Health Organization, Geneva, Switzerland, 2007.

[11] I. Kosalec, J. Cvek, and S. Tomić, "Contaminants of medicinal herbs and herbal products," Arhiv Za Higijenu Rada I Toksikologiju, vol. 60, pp. 485-501, 2009.

[12] E. A. Elkhair, H. Fadda, and U. A. Mohsen, “Antibacterial activity and Phytochemical analysis of some medicinal plants from Gaza Strip-Palestine," Journal of Al Azhar UniversityGaza, vol. 12, pp. 45-54, 2010.

[13] Ministry of Palestinian Health, Instructions for Registration and Trading of Medicinal Plants and Food Supplements, Ministry of Palestinian Health, Nablus, Palestine, 2020.

[14] FAO, "Contaminants," in Codex Alimentarius, FAO/WHO, Codex Alimentarius Commision, FAO, Rome, Italy, First edition, 1984.

[15] World Health Organization, Quality Control Methods for Medicinal Plant Materials, World Health Organization, Geneva, Switzerland, 2005.

[16] M. Abualhasan, N. Jaradat, Z. Sawaftah, H. Mohsen, D. Najjar, and W. Zareer, "Evaluation of heavy metals and microbiological contamination of selected herbals from Palestine," Open Life Sciences, vol. 14, p. 448, 2019.

[17] A. Tariq, M. Adnan, A. Iqbal et al., "Ethnopharmacology and toxicology of Pakistani medicinal plants used to treat gynecological complaints and sexually transmitted infections," South African Journal of Botany, vol. 114, pp. 132-149, 2018.

[18] N. Khan, A. M. Abbasi, G. Dastagir et al., "Ethnobotanical and antimicrobial study of some selected medicinal plants used in Khyber Pakhtunkhwa (KPK) as a potential source to cure infectious diseases," BMC Complementary and Alternative Medicine, vol. 14, p. 122, 2014.

[19] A. Majid, H. Ahmad, Z. Saqib et al., "Exploring threatened traditional knowledge; ethnomedicinal studies of rare endemic flora from Lesser Himalayan region of Pakistan," Revista Brasileira de Farmacognosia, vol. 29, pp. 785-792, 2019.

[20] C. Walther, K. J. Marwa, J. Seni et al., "Microbial contamination of traditional liquid herbal medicinal products marketed in Mwanza city: magnitude and risk factors," Pan African Medical Journal, p. 65, 2016.

[21] G. Di Bella and A. G. Potortì, "Organic contamination of Italian and Tunisian culinary herbs and spices," Journal of Environmental Science and Health, vol. 54, pp. 345-356, 2019.

[22] M. A. Nkansah, S. T. Hayford, L. S. Borquaye, and J. H. Ephraim, "Heavy metal contents of some medicinal herbs from Kumasi, Ghana," Cogent Environmental Science, vol. 2, p. 1234660, 2016.

[23] I. A. Adeleye, G. Okogi, and E. O. Ojo, "Microbial contamination of herbal preparations in Lagos, Nigeria," Journal of Health, Population, and Nutrition, vol. 23, pp. 296-297, 2005.

[24] A. C. B. Carvalho, T. N. Lana, J. P. S. Perfeito, and D. Silveira, "The Brazilian market of herbal medicinal products and the impacts of the new legislation on traditional medicines," Journal of Ethnopharmacology, vol. 212, pp. 29-35, 2018.

[25] A. Okem, C. Southway, W. A. Stirk, R. A. Street, J. F. Finnie, and J. Van Staden, "Heavy metal contamination in South African medicinal plants: a cause for concern," South African Journal of Botany, vol. 93, pp. 125-130, 2014.

[26] M. Hashem and S. Alamri, "Contamination of common spices in Saudi Arabia markets with potential mycotoxin-producing fungi," Saudi Journal of Biological Sciences, vol. 17, pp. 167175, 2010.

[27] N. M. Abdulla, B. Adam, I. Blair, and A. Oulhaj, "Heavy metal content of herbal health supplement products in Dubai - UAE: a cross-sectional study," BMC Complementary and Alternative Medicine, vol. 19, p. 276, 2019.

[28] B. Saad, H. Azaizeh, G. Abu-Hijleh, and O. Said, "Safety of traditional arab herbal medicine," Evid Based Complement Alternat Med, vol. 3, pp. 433-439, 2006.

[29] R. A. Street, "Heavy metals in medicinal plant products - an African perspective," South African Journal of Botany, vol. 82, pp. 67-74, 2012.

[30] M. A. A. Donia, "Microbiological quality and aflatoxinogenesis of egyptian spices and medicinal plants," Global Veterinaria, vol. 2, 2008.

[31] G. Yaqub, F. Ilyas, M. Idrees, and V. Mariyam, "Monitoring and risk assessment due to presence of heavy metals and pesticides in tea samples," Food Science and Technology, vol. 38, pp. 625-628, 2018.

[32] L. Nkuba and N. Mohammed, "Heavy metals and essential elements in selected medicinal plants commonly used for medicine in Tanzania," Chemical Science International Journal, vol. 19, pp. 1-11, 2017. 
[33] A. Umar, Y. Mohammed, S. Garba, and M. Faruruwa, "Quantitative determination of heavy metals in some commonly consumed herbal medicines in Kano State, Nigeria," Journal of Scientific and Engineering Research, vol. 3, pp. 1-8, 2016.

[34] R. Dghaim, S. Al Khatib, H. Rasool, and M. Ali Khan, "Determination of heavy metals concentration in traditional herbs commonly consumed in the United Arab Emirates," Journal of Environmental and Public Health, vol. 2015, 2015.

[35] C. M. de Sousa Lima, M. A. T. Fujishima, B. de Paula Lima, P. C. Mastroianni, F. F. O. de Sousa, and J. O. da Silva, "Microbial contamination in herbal medicines: a serious health hazard to elderly consumers," BMC Complementary Medicine and Therapies, vol. 20, p. 17, 2020.

[36] F. Carraturo, O. De Castro, J. Troisi et al., "Comparative assessment of the quality of commercial black and green tea using microbiology analyses," BMC Microbiol, vol. 18, p. 4, 2018.

[37] M. Abualhasan, A. Basim, A. salahat, S. Sofan, and M. AlAtrash, "Quality of water used in Palestinian hemodialysis centers," Public Health, vol. 165, pp. 136-141, 2018.

[38] United State Pharmacopoeia, 2017.

[39] A. Abu-Rabia, "Herbs as a food and medicine source in Palestine," Asian Pacific Journal of Cancer Prevention: APJCP, vol. 6, pp. 404-407, 2005.

[40] V. Chunilall, A. Kindness, and S. B. Jonnalagadda, "Heavy metal uptake by two edible Amaranthus herbs grown on soils contaminated with lead, mercury, cadmium, and nickel," Journal of Environmental Science and Health, Part B, vol. 40, pp. 375-384, 2005.

[41] T. Ekar and S. Kreft, "Common risks of adulterated and mislabeled herbal preparations," Food and Chemical Toxicology, vol. 123, pp. 288-297, 2019.

[42] S. Sharma, "Current status of herbal product: regulatory overview," J Pharm Bioallied Sci, vol. 7, pp. 293-296, 2015.

[43] V. Vergote, C. Burvenich, C. Van de Wiele, and B. De Spiegeleer, "Quality specifications for peptide drugs: a regulatory-pharmaceutical approach," Journal of Peptide Science, vol. 15, pp. 697-710, 2009.

[44] M. Louis, L. Leblanc, and F. A. Montero Julian, "Introduction to culture media in pharmaceutical microbiology for nonsterile products," Pharmaceutical Microbiological Quality Assurance and Control, pp. 79-104, 2019.

[45] V. Mugoyela and K. D. Mwambete, "Microbial contamination of nonsterile pharmaceuticals in public hospital settings," Ther Clin Risk Manag, vol. 6, pp. 443-448, 2010.

[46] D. Pullirsch, J. Bellemare, A Hackl et al., "Microbiological contamination in counterfeit and unapproved drugs," BMC Pharmacology and Toxicology, vol. 15, p. 34, 2014. 